\title{
The elusive $\equiv \mathrm{C}-\mathrm{H} \cdots$ O complex in the hydrogen bonded systems of Phenylacetylene: A Matrix Isolation Infrared and $A b$ Initio Study
}

\author{
GINNY KARIR ${ }^{\mathrm{a}}$, MARIYAM FATIMA ${ }^{\mathrm{a}, \mathrm{b}}$ and K S VISWANATHAN ${ }^{\mathrm{a}, *}$ \\ a Department of Chemical Sciences, Indian Institute of Science Education and Research, Sector 81, Mohali, \\ Punjab, 140306 India \\ ${ }^{b}$ Present address: Max-Planck-Institut für Struktur und Dynamik der Materie, Luruper Chaussee 149, \\ D-22761 Hamburg, Germany \\ e-mail: vish@iisermohali.ac.in
}

MS received 1 August 2016; revised 19 August 2016; accepted 19 August 2016

\begin{abstract}
Hydrogen-bonded complexes of phenylacetylene (PhAc) with methanol (MeOH) and diethylether (DEE) were studied using matrix isolation infrared spectroscopy. This study specifically searched for the $\equiv \mathrm{C}$ $\mathrm{H}$... O hydrogen bonded complex in these systems, which manifest a n- $\sigma *$ interaction and which is a local minimum on the PhAc-MeOH potential surface, as in the case of $\mathrm{PhAc}-\mathrm{H}_{2} \mathrm{O}$ heterodimer. This $\mathrm{n}-\sigma^{*}$ local minimum eluded observation in gas phase studies and it was therefore thought interesting to look for this isomer in cryogenic matrices. While $\mathrm{MeOH}$ can interact with $\mathrm{PhAc}$ as both a proton donor $(\mathrm{O}-\mathrm{H} \cdots \pi \mathrm{complex})$ or a proton acceptor ( $n-\sigma^{*}$ complex), DEE can only manifest the $n-\sigma^{*}$ isomer. A comparison of the spectral shifts observed in the features of PhAc-MeOH and PhAc-DEE would therefore independently confirm the existence or not of $n-\sigma^{*}$ complex in both these systems. In addition to the $n-\sigma *$ complex observed in both the above systems, the $\mathrm{O}-\mathrm{H} \cdots \pi$ complex was also discerned in the PhAc-MeOH system. These complexes have stabilization energy in the range of $8-25 \mathrm{~kJ} / \mathrm{mol}$. The experimental results were corroborated by computations performed at MP2 and M06-2X, levels of theory, using 6-311++G(d,p) and aug-cc-pVDZ basis sets. Single point calculations at the CCSD level of theory were also performed. Atoms-in-molecules (AIM), NBO and LMOEDA analysis were also performed to understand the nature of the intermolecular interactions in these complexes.
\end{abstract}

Keywords. Methanol; hydrogen bonded systems; Diethyl ether; ab initio computations; matrix isolation; infrared spectroscopy.

\section{Introduction}

A deep understanding of the weak, yet significant non-covalent interactions is imperative in rationalizing many chemical, physical and biochemical processes. Consequently, studies on weak interactions have received a strong impetus in the last many decades. There are many reports in the literature, where hydrogen bonding interactions have been studied experimentally and computationally. ${ }^{1-7}$ Interestingly, hydrogen bonding comes in many 'shades and hues', with a variety of proton donors and acceptors. Proton donors range from the conventional $\mathrm{O}-\mathrm{H}$ and $\mathrm{N}-\mathrm{H}$ to the less traditional C-H and $\mathrm{S}-\mathrm{H}$ groups. Likewise, proton acceptance has been observed on traditional lone-pair containing atoms such as $\mathrm{O}$ and $\mathrm{N}$ to interesting groups such as $\pi$-electron systems, such as acetylene

*For correspondence

Celebrating 100 years of Lewis Chemical Bond and benzene. ${ }^{8,9}$ The strength and the nature of hydrogen bond contacts between interacting partners depend essentially on the precursors, which in turn govern their behavior in physico-chemical systems. Hence, a comprehensive knowledge of hydrogen bonding can prove to be advantageous for deciphering and predicting structure-function relationship between chemical species.

Amongst the many techniques used for studying hydrogen bonding interactions, matrix isolation and supersonic jet expansion methods have become the techniques of choice, because of the highly resolved spectra that they offer, which consequently makes it possible to make unambiguous assignments of hydrogen bonded structures. ${ }^{10,11}$ In addition, the two technqiues very often prove to be complementary; while the supersonic jet technique prepares species in their lowest energy structure, the global minimum, matrix isolation spectroscopy traps structures both in the global and local minima. The two studies therefore allow for a more complete understanding of the potential 
surface of the weak complexes. For example, in the study of $\mathrm{PhAc}-\mathrm{H}_{2} \mathrm{O}$ complex, while the molecular beam studies identified the global minimum, which was an $\mathrm{O}-\mathrm{H} \cdots \pi$ complex (additionally stabilized by a phenyl C-H $\cdots \mathrm{OH}_{2}$ interaction), matrix isolation studies unambiguously trapped an $\mathrm{n}-\sigma^{*}(\equiv \mathrm{C}-\mathrm{H} \cdots \mathrm{O})$ complex, which was a local minimum. The two studies together therefore led to a better understanding of the $\mathrm{PhAc}-\mathrm{H}_{2} \mathrm{O}$ system. ${ }^{12-14}$

The PhAc-methanol $(\mathrm{MeOH})$ system offers a similar dichotomy. Computation on $\mathrm{PhAc}-\mathrm{MeOH}$ indicated two types of nearly degenerate $\mathrm{O}-\mathrm{H} \cdots \pi$ complexes, where $\mathrm{MeOH}$ donates a proton to the $\pi$ system of either the benzene ring or the acetylenic system of PhAc. Gas phase studies, using UV-IR double resonance as the probe, clearly identified the $\mathrm{O}-\mathrm{H} \cdots \pi$ complex. It was inferred in these experiments that the observed complex was one where $\mathrm{MeOH}$ donated its hydroxyl proton to the phenyl ring of PhAc. ${ }^{15}$ Furthermore, the $\mathrm{n}-\sigma^{*}$ complex, where $\mathrm{PhAc}$ donates a proton to the oxygen of $\mathrm{MeOH}$ was not observed in their experiments, though computations indicated this complex to be a local minimum, which was only marginally less stable than the $\mathrm{O}-\mathrm{H} \cdots \pi$ global minimum. It was therefore thought interesting to examine if this local minimum could be observed in the matrix, much like in the $\mathrm{PhAc}-\mathrm{H}_{2} \mathrm{O}$ system.

To independently confirm the presence of the $n-\sigma^{*}$ complex in the matrix, we also performed experiments with diethylether (DEE), to study the hydrogen bonded complex of PhAc-DEE. This system can be expected to manifest only the $\mathrm{n}-\sigma^{*}$ complex. A comparison of the shifts in the $\equiv \mathrm{C}-\mathrm{H}$ vibrational frequency in PhAcDEE with that observed for $\mathrm{PhAc}-\mathrm{H}_{2} \mathrm{O}$ and $\mathrm{PhAc}-$ $\mathrm{MeOH}$ would unambiguously confirm the presence of this type of interaction in these complexes, which was the motivation for our studies with DEE.

\section{Experimental and Computational}

Matrix isolation experiments were carried out using a He compressor cooled cryostat, CH-202 W/HC 4E1 Model Sumitomo Heavy Industries Ltd., to achieve $12 \mathrm{~K}$. A KBr substrate was mounted on the cryotip, onto which the sample was deposited. The cryostat was housed in a vacuum chamber where the base pressure was $\sim 10^{-6}$ torr. The details of the experiments are described elsewhere. ${ }^{16-19}$ In particular, the present set of experiments was performed using $\mathrm{N}_{2}$ and $\mathrm{Ar}$ (Sigma Gases and Services, 99\%) as matrix gases. Phenylacetylene (Sigma Aldrich, 98\%), Phenylacetylene-D (Sigma Aldrich, 99\% Atom-D), $\mathrm{MeOH}$ (Merck $\geq 99.8$ ) and diethylether (Merck 299.8 ) were used without further purification. All liquid samples were used after subjecting them to several freeze-pump-thaw cycles, before preparation of the matrix gas-sample mixture.

Matrix gas-sample mixture was deposited on the cold substrate using a single jet effusive nozzle. Typical deposition rates were $\sim 3 \mathrm{mmol} / \mathrm{h}$ of the matrix gas, achieved using a needle valve (Model: EVN 116, Pfeiffer Vacuum). The concentration of matrix gas-sample was varied typically from $0.5: 1000$ to $3: 1000$ individually, for both precursors using simple mannometric procedures.

The spectra of the matrix isolated species, were recorded in the region $4000-400 \mathrm{~cm}^{-1}$ using a Bruker Tensor 27 FTIR spectrometer, at a resolution $0.5 \mathrm{~cm}^{-1}$. The matrix was then annealed at $27 \mathrm{~K}\left(\mathrm{~N}_{2}\right)$ or $32 \mathrm{~K}$ (Ar), and the spectrum again recorded after recooling the matrix to $12 \mathrm{~K}$, to observe the product bands. Experiments were performed in both $\mathrm{Ar}$ and $\mathrm{N}_{2}$ matrices, both of which showed evidence for the formation of the $\mathrm{PhAc}-\mathrm{MeOH}$ and PhAc-DEE complexes. However, since the spectra were well resolved in the $\mathrm{N}_{2}$ matrix, we show the spectra obtained in this matrix.

\subsection{Computational Details}

The computational study was carried out using Gaussian-09 suite of programs. ${ }^{20}$ All computations were performed at M06-2X and MP2 levels, using 6-311++G(d,p) and aug-cc-pVDZ basis sets. Geometry optimization of monomers was first done. Using the optimized monomer geometries, the geometries of PhAc-MeOH and PhAc-DEE complexes were then optimized. Frequency calculations were performed at the same level of theory as that used for geometry optimization. Vibrational frequency computations were done to ensure that the computed structures corresponded to minima on the potential surface and also to assign the vibrational features observed in the experiments. The computed frequencies of the complexes, $\mathrm{PhAc}-\mathrm{MeOH}$ and PhAc-DEE were scaled by using appropriate scaling factors to enable a comparison with experimentally observed features. The scale factors were computed by comparing the computed frequencies of monomeric $\mathrm{MeOH}$ for $\mathrm{PhAc}-\mathrm{MeOH}$ complexes, with the observed experimental frequencies, in a given matrix, to bring them in agreement with the experimental vibrational frequencies of the complexes. For a better comparison, we have used two different scale factors in this work; one applicable for the region 3900-3000 $\mathrm{cm}^{-1}$ derived by using $\mathrm{O}-\mathrm{H}$ stretch of $\mathrm{MeOH}$ for comparison, and another for the region $3000-500 \mathrm{~cm}^{-1}$ 
obtained by comparing the computed and experimental wavenumber of the $\mathrm{C}-\mathrm{O}$ stretch of $\mathrm{MeOH}$. These two scale factors were then used to scale the computed features of the all the species, $\mathrm{PhAc}, \mathrm{MeOH}$ and PhAc$\mathrm{MeOH}$ complexes. Similarly, PhAc-DEE complexes were also scaled using two different scaling factors derived by using $\equiv \mathrm{C}-\mathrm{H}$ stretch of $\mathrm{PhAc}$ and C-O stretch of DEE for the regions $3500-2000 \mathrm{~cm}^{-1}$ and $1630-500$ $\mathrm{cm}^{-1}$, respectively. The scale factors have been mentioned in each of the tables listing the experimental and computed vibrational wavenumbers. Vibrational spectra were simulated using the scaled vibrational wavenumbers and the intensity obtained from the vibrational analysis implemented through Gaussian. All computed spectra for the precursors and the complexes were plotted using spectrum synthesis program, Synspec, ${ }^{21}$ and were compared with the experimental spectra. Synspec spectra were obtained using Lorentzian lineshape and a full width at half maximum (FWHM) of $1.0 \mathrm{~cm}^{-1}$.

The interaction energies of the complexes were calculated from the energies of the complexes and the monomers. These interaction energies were corrected separately for basis set superposition error (BSSE), using counterpoise method proposed by Boys and Bernardi $^{22}$ and ZPE (zero point energies). Interaction energies using single point calculation at the CCSD/ 6-311++G(d,p) and CCSD/aug-cc-pVDZ level were also calculated using the geometry optimized at the MP2 level and the respective basis sets. An examination of electron density topology was performed using the atoms-in-molecules analysis implemented through AIM2000, ${ }^{23}$ to understand bonding characteristics in the complex. $\mathrm{NBO}^{24}$ and LMOEDA ${ }^{25}$ analysis, implemented using Gaussian-09 and GAMESS, ${ }^{26}$ respectively, were also performed to understand the nature of bonding in these non-covalent interactions.

We will first present our results on PhAc-Methanol complex and then on PhAc-DEE complex.

\section{Results and Discusssion}

\section{$3.1 \quad \mathrm{PhAc}-\mathrm{MeOH}$}

3.1.1 Experimental: When $\mathrm{PhAc}$ and $\mathrm{MeOH}$ were codeposited and the matrix then annealed, new product features were observed at $3235.1 / 3232.6 \mathrm{~cm}^{-1}$ in the region of the $\equiv \mathrm{CH}$ stretch of $\mathrm{PhAc}$ (Figure 1) and 3593.9/3590.6 in the region of $\mathrm{MeOH} \mathrm{O}-\mathrm{H}$ stretch (Figure 2). These features were observed only when both precursors were codeposited and the matrix was annealed. Furthermore, on increasing the concentration of either monomer, the intensity of the product features increased, thereby confirming them to be

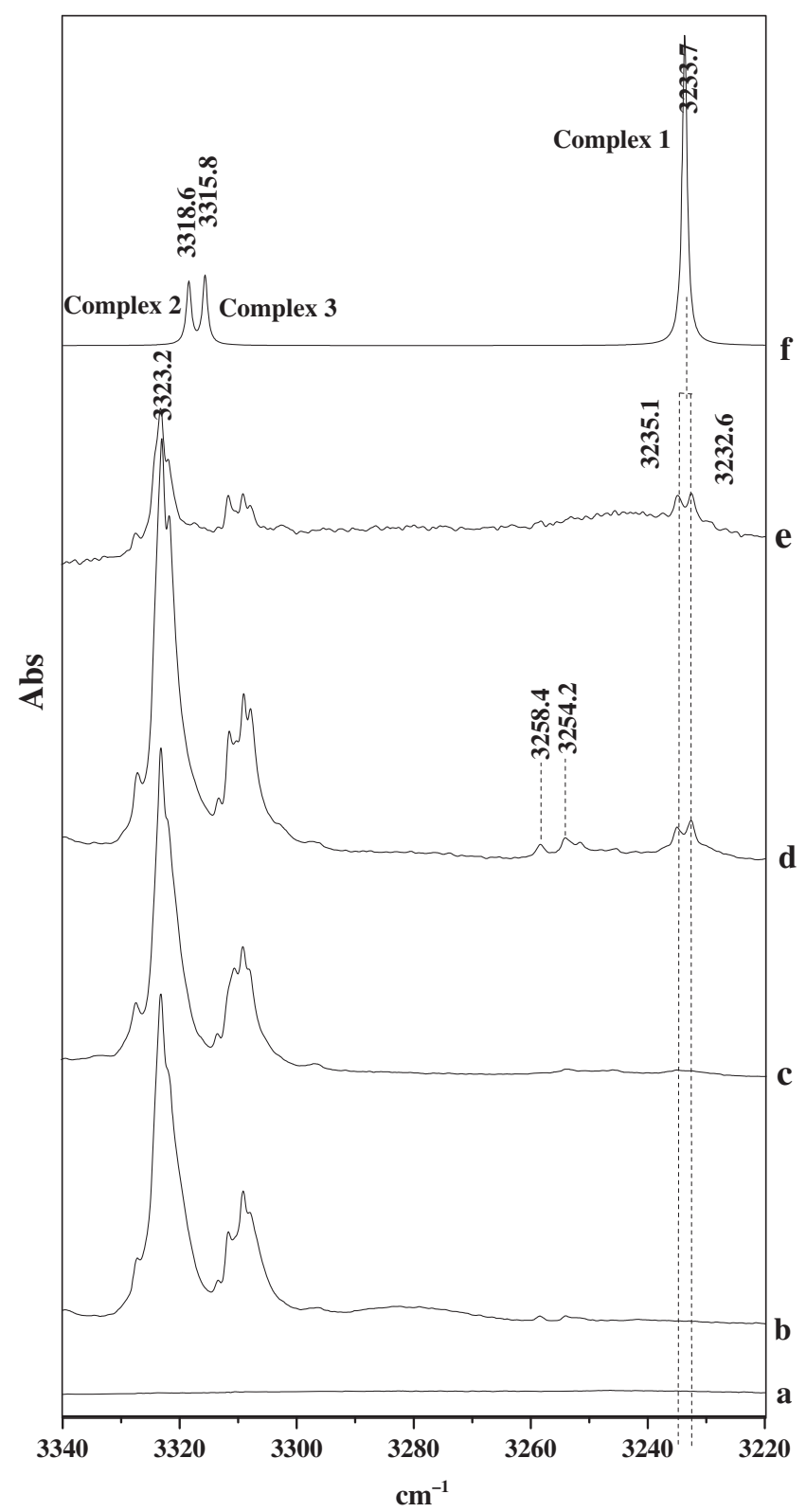

Figure 1. Annealed spectra of $\mathrm{PhAc}, \mathrm{MeOH}$ and $\mathrm{PhAc}-$ $\mathrm{MeOH}$ complex in $\equiv \mathrm{CH}$ stretching region of $\mathrm{PhAc}$ (3440-3220 cm ${ }^{-1}$ ). (a) $\mathrm{MeOH}: \mathrm{N}_{2}(1: 1000)$ (b) $\mathrm{PhAc}: \mathrm{N}_{2}$ (3:1000) (c) $12 \mathrm{~K}$ spectrum of PhAc:MeOH: $\mathrm{N}_{2}$ (3:1:1000) (d) PhAc: $\mathrm{MeOH}: \mathrm{N}_{2} \quad$ (3:1:1000). (e) PhAc:MeOH:N (0.5:1:1000) (f) Computed Spectra of Compex 1, 2 and 3 at MP2/aug-cc-pVDZ level of theory.

due to the $\mathrm{PhAc}-\mathrm{MeOH}$ complex. Experiments were also performed at very low concentration of both the monomers thereby excluding the possibility of these features being due to dimers or other higher aggregates of the monomeric species. Furthermore, low concentration experiments also confirmed these complexes as 1:1 adducts rather than larger hydrogen bonded clusters. Experiments with isotopically substituted $\mathrm{PhAc}$ with acetylenic hydrogen replaced with deuterium $\left(\mathrm{PhAc}_{\mathrm{D}}\right)$ 


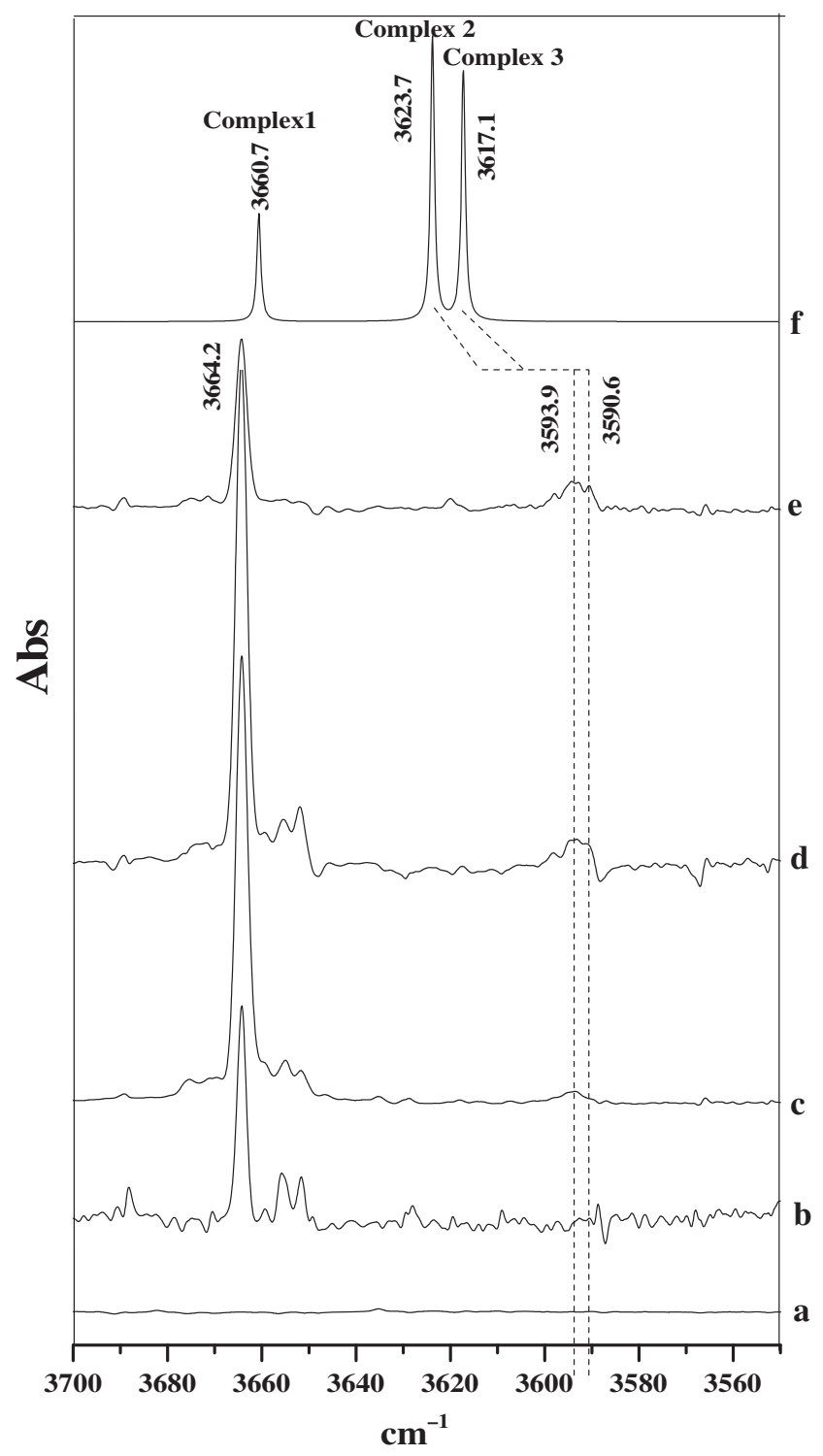

Figure 2. Annealed spectra of $\mathrm{PhAc}, \mathrm{MeOH}$ and $\mathrm{PhAc}-$ $\mathrm{MeOH}$ complex in $\mathrm{OH}$ stretching region of $\mathrm{PhAc}(3700$ $3550 \mathrm{~cm}^{-1}$ ). (a) $\mathrm{MeOH}: \mathrm{N}_{2}(1: 1000)$ (b) $\mathrm{PhAc}: \mathrm{N}_{2}(3: 1000)$ (c) $12 \mathrm{~K}$ spectrum of PhAc:MeOH: $\mathrm{N}_{2}$ (3:3:1000) (d) PhAc:MeOH: $\mathrm{N}_{2}$ (3:3:1000). (e) PhAc:MeOH:N $\mathrm{N}_{2}$ (3:1:1000) (f) Computed Spectra of Compex 1, 2 and 3 at MP2/aug-ccpVDZ level of theory.

were also performed to observe isotopic shifts. Product features were observed at 2554.7 and $2593.6 \mathrm{~cm}^{-1}$ in $\mathrm{N}_{2}$ matrix (Figure 3).

3.1.2 Computational: Ab-initio calculations performed at MP2/6-311++G(d,p) and MP2/aug-cc-pVDZ level of theory yielded three hydrogen bonded complexes as a minima on potential energy surface. The structures of $\mathrm{PhAc}-\mathrm{MeOH}$ complexes at MP2/aug-cc-pVDZ level are shown in Figure 4 and agree with those reported by Singh and Patwari. ${ }^{15}$ Complex 1 represents an $n-\sigma^{*}$

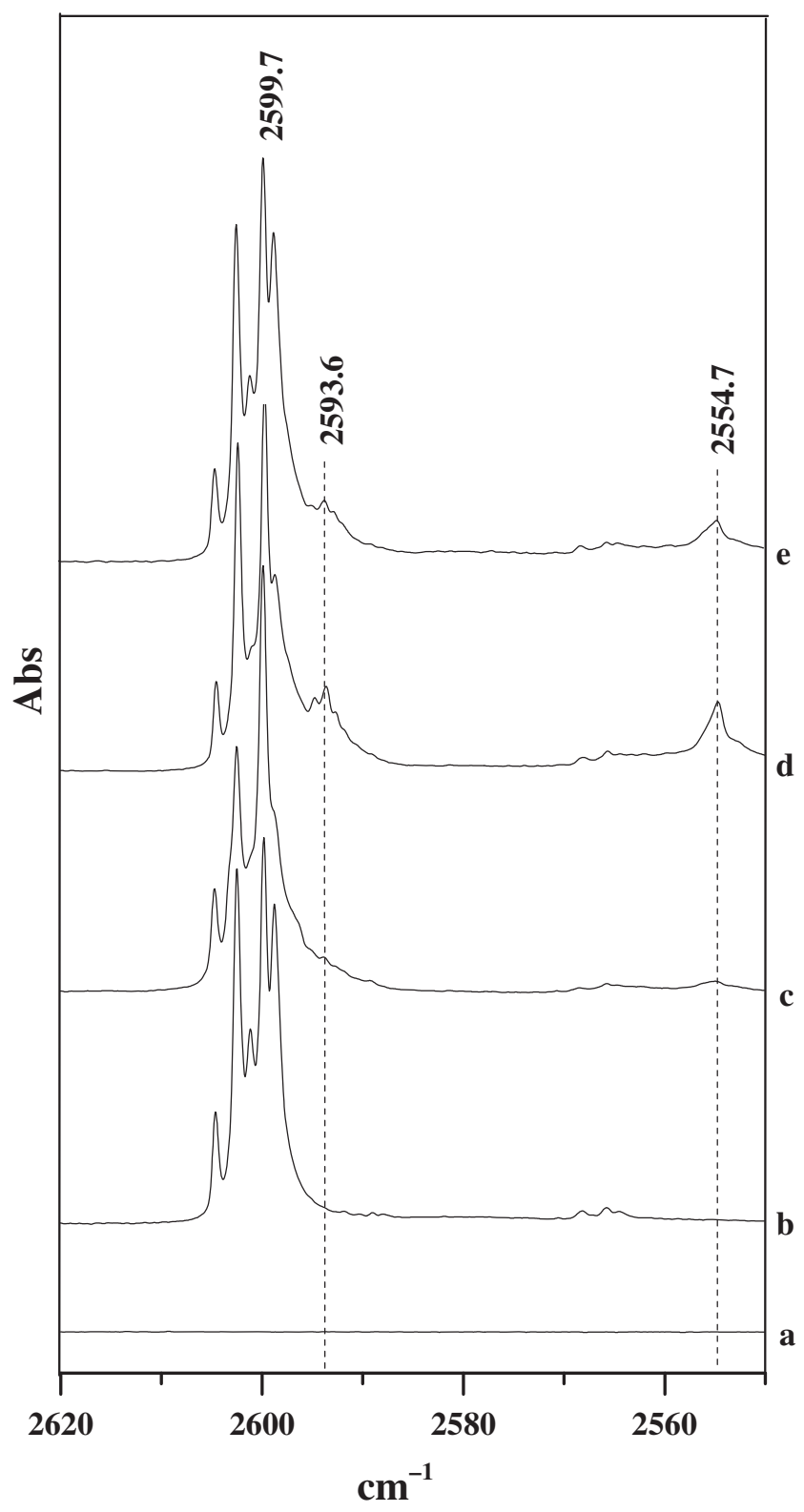

Figure 3. Annealed spectra of $\mathrm{PhAcD}, \mathrm{MeOH}$ and $\mathrm{PhAcD}-\mathrm{MeOH}$ complex in $\equiv \mathrm{CD}$ stretching region of $\mathrm{PhAcD}$ (2650-2500 $\mathrm{cm}^{-1}$ ). (a) MeOH: $\mathrm{N}_{2}(1: 1000)$ (b) PhAcD $: \mathrm{N}_{2}$ (3:1000) (c) $12 \mathrm{~K}$ spectrum of PhAcD:MeOH: $\mathrm{N}_{2}$ (3:3:1000) (d) PhAcD:MeOH:N $\mathrm{N}_{2}$ (3:3:1000). (e) PhAcD:MeOH:N (3:1:1000).

complex in which $\mathrm{PhAc}$ acts as proton donor through acetylenic $\mathrm{C}-\mathrm{H}$ to oxygen of $\mathrm{MeOH}$. Two other structures represent $\mathrm{O}-\mathrm{H} \cdots \pi$ systems, where the $\mathrm{MeOH}$ serves as a proton donor to the $\pi$ system of the phenyl ring (Complex 2) or the acetylenic system (Complex 3). At this level of theory, Complex 2 is the global minimum, while Complex 3 is only marginally higher in energy, by about $0.4 \mathrm{~kJ} / \mathrm{mol}$. At the M06-2X level of theory in addition to these three complexes a fourth complex (Complex 4) was also located. This complex has an interaction between the $\mathrm{O}-\mathrm{H}$ group of $\mathrm{MeOH}$ 


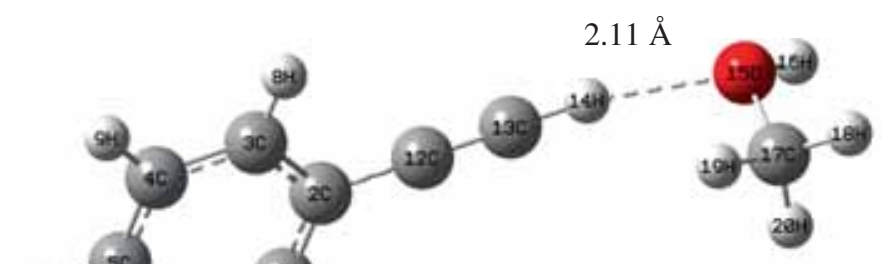

Complex 1

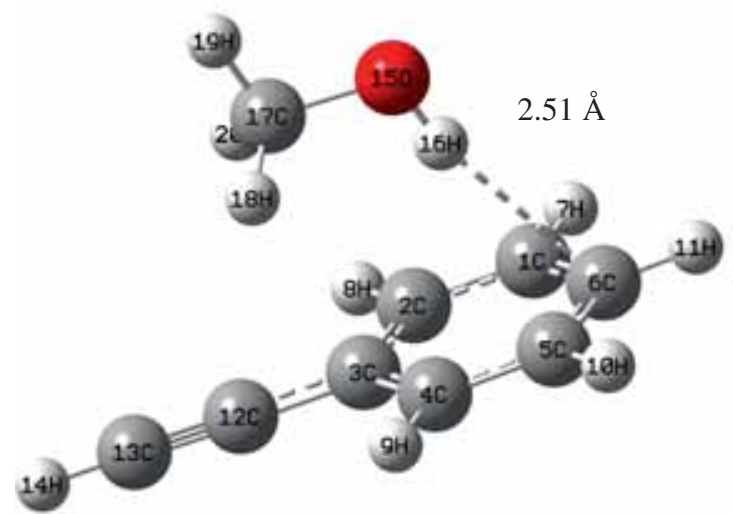

Complex 2

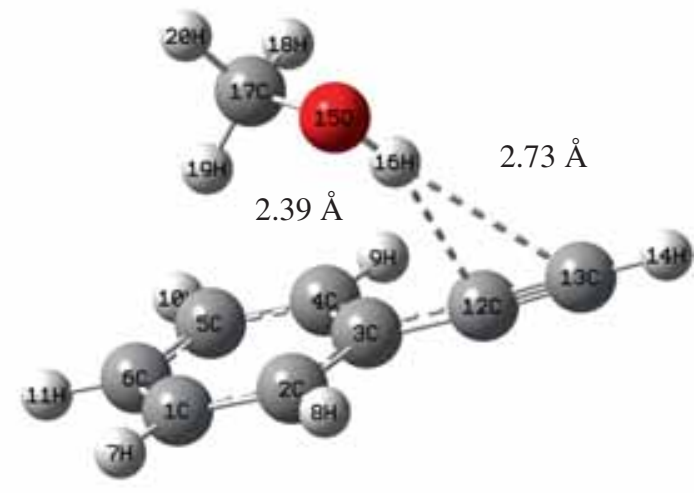

Complex 3

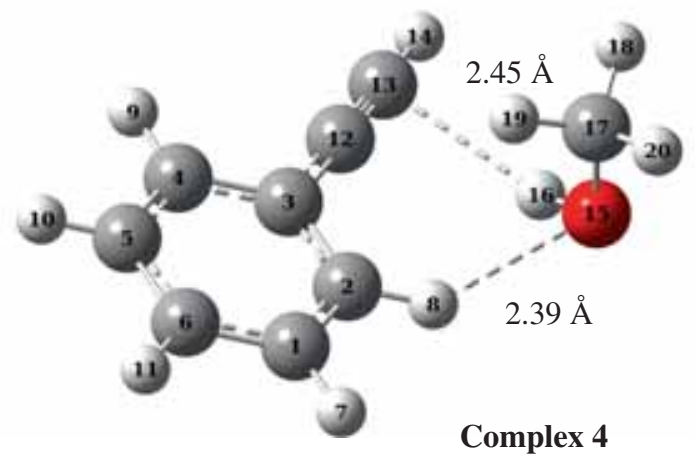

Figure 4. Optimized geometries of PhAc-MeOH complexes at MP2/aug-cc-pVDZ level of theory. Note that the structure of Complex 4 shown, was obtained at M06-2X/aug-cc-pDVZ level of theory. See text for details.

and the acetylenic $\pi$ cloud of PhAc, together with a $\mathrm{C}-\mathrm{H} \cdots \mathrm{O}$ interaction between hydrogen atom attached to ortho $\mathrm{C}$ of $\mathrm{PhAc}$ and $\mathrm{O}$ of $\mathrm{MeOH}$; very similar to the PhAc- $\mathrm{H}_{2} \mathrm{O}$ structure, which was the global minimum (Figure 4, Table S1 in Supplementary Information). This structure was not found at the MP2 level. The Raw/ZPE/BSSE corrected interaction energies of $\mathrm{PhAc}-\mathrm{MeOH}$ complexes at various levels of theory are given in Table 1. Table 1 shows that at the M06-2X level of theory Complex 4 is the lowest energy structure whereas at the MP2 level, Complex 2 is the global minimum. Since Complex 4 occurs only at the M06-2X level and not at the MP2, we refrain from discussing this structure further. It is clear that in systems with weakly interacting contacts, a number of isomers are possible and the energy ordering amongst these structures can often be ambiguous and a function of the level of theory employed. Answer to energy ordering of the various isomers can be provided only with experimental results together with computations. In the case of $\mathrm{PhAc}-\mathrm{MeOH}$, but for the experimental data of Singh and Patwari, ${ }^{15}$ the issue of the global minimum would have been an open question. Experiments, such as ours, which probe local minima, lead to an enhanced understanding of the system. Table S1 (in Supplementary Information) gives the details of geometrical parameters of PhAc-MeOH complexes at MP2/aug-cc-pVDZ level of theory. 
Table 1. Computed interaction energies Raw/ZPE/BSSE $(\mathrm{kJ} / \mathrm{mol})$ of the complexes of PhAc-MeOH, at various levels of theory and basis sets. CCSD values are uncorrected interaction energies obtained using single point energy calculations at the geometries optimized at the MP2 level and the corresponding basis sets.

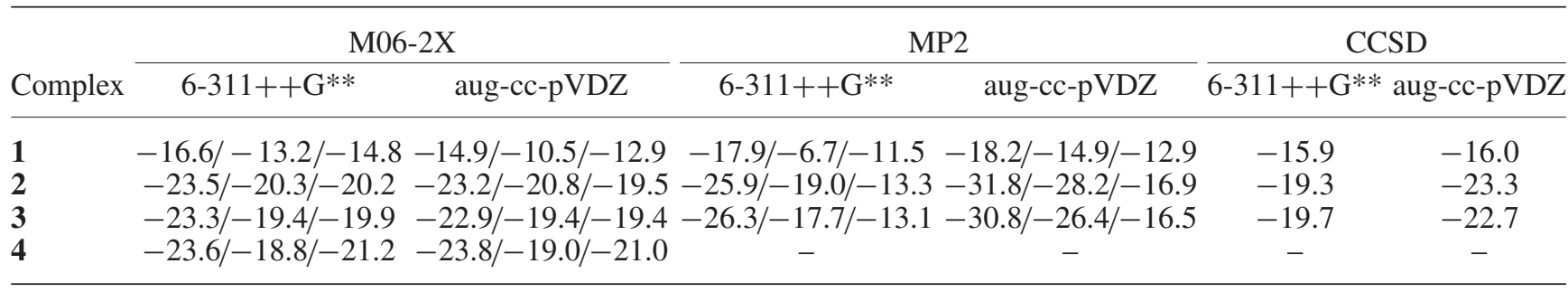

Table 2. Experimental and scaled ${ }^{1}$ computed wavenumbers $\left(\mathrm{cm}^{-1}\right)$ for $\mathrm{PhAc}-\mathrm{MeOH}$ complexes at MP2/aug-cc-pVDZ level of theory.

\begin{tabular}{|c|c|c|c|c|c|c|}
\hline \multicolumn{2}{|c|}{ Experimental $\left(\mathrm{N}_{2}\right)$} & \multicolumn{4}{|c|}{ Scaled Computed Wavenumbers $\left(\mathrm{cm}^{-1}\right)$} & \multirow{2}{*}{$\begin{array}{c}\text { Mode } \\
\text { Assignment }\end{array}$} \\
\hline & Complex & Monomer & Complex 1 & Complex 2 & Complex 3 & \\
\hline \multicolumn{7}{|l|}{$\mathrm{PhAc}$} \\
\hline 3323.2 & $\begin{array}{c}3235.1 / 3232.6 \\
(-\mathbf{8 8 . 1})^{2} /(-\mathbf{9 0 . 6})\end{array}$ & 3320.5 & $\begin{array}{l}3233.7 \\
(-\mathbf{8 6 . 9})\end{array}$ & $\begin{array}{l}3318.6 \\
(-2.0)\end{array}$ & $\begin{array}{l}3315.8 \\
(-4.8)\end{array}$ & $\equiv \mathrm{CH}$ stretch \\
\hline $\mathrm{CH}_{3} \mathrm{OH}$ & & & & & & \\
\hline 3664.2 & $\begin{array}{l}3593.9 / 3590.6 \\
(-\mathbf{7 0 . 3} / \mathbf{- 7 3 . 6})\end{array}$ & 3664.3 & $\begin{array}{l}3660.7 \\
(-3.6)\end{array}$ & $\begin{array}{l}3623.7 \\
(-\mathbf{4 0 . 6})\end{array}$ & $\begin{array}{l}3617.1 \\
(-\mathbf{4 7 . 2})\end{array}$ & $\mathrm{OH}$ stretch \\
\hline $\begin{array}{l}\mathrm{PhAc}_{\mathrm{D}} \\
2599.7\end{array}$ & $\begin{array}{c}2554.7 \\
(-\mathbf{4 5 . 0}) \\
2593.6 \\
(-\mathbf{6 . 1})\end{array}$ & 2652.2 & $\begin{array}{l}2599.9 \\
(-\mathbf{5 2 . 3})\end{array}$ & $\begin{array}{l}2650.7 \\
(-\mathbf{1 . 5})\end{array}$ & $\begin{array}{l}2647.7 \\
(-4.5)\end{array}$ & $\equiv \mathrm{CD}$ stretch \\
\hline
\end{tabular}

${ }^{1}$ Scaling Factor $\left(500-3000 \mathrm{~cm}^{-1}\right)=0.99089$; Scaling Factor $\left(3000-3900 \mathrm{~cm}^{-1}\right)=0.95385$.

${ }^{2} \Delta v=v_{\text {complex }}-v_{\text {monomer }}$.

\subsubsection{Vibrational Assignments}

3.1.3a $\equiv C$-H stretch of PhAc in PhAc-MeOH: The $\mathrm{PhAc}$ in $\mathrm{N}_{2}$ matrix shows $\equiv \mathrm{C}-\mathrm{H}$ frequency at 3323.2 $\mathrm{cm}^{-127}$ with Fermi resonance diad appearing at $3309.2 / 3310.8 \mathrm{~cm}^{-1}$; this doublet being due to site splitting. The Fermi resonance has been reported to occur between the $\equiv \mathrm{C}-\mathrm{H}$ stretch and a combination of one quantum of $\mathrm{C} \equiv \mathrm{C}$ stretch and two quanta of $\mathrm{C} \equiv \mathrm{C}$ $\mathrm{H}$ out-of-plane bend. ${ }^{28}$ New product features at 3235.1 $\mathrm{cm}^{-1} / 3232.6 \mathrm{~cm}^{-1}$ were seen when $\mathrm{PhAc}$ and $\mathrm{MeOH}$ were codeposited in the matrix. These product features were assigned to the $\equiv \mathrm{C}-\mathrm{H}$ stretch of $\mathrm{PhAc}$ in $\mathrm{PhAc}$ $\mathrm{MeOH}$ complex (Figure 1). Table 2 shows that this feature was red shifted from $\equiv \mathrm{C}-\mathrm{H}$ stretch of monomer $\mathrm{PhAc}$ by $88.1 \mathrm{~cm}^{-1}$. This shift is in good agreement with the computed wavenumber shift of $\sim 87 \mathrm{~cm}^{-1}$ for Complex 1. PhAc being the proton donor shows large red shift which is in agreement with our previous work on $\mathrm{PhAc}-\mathrm{H}_{2} \mathrm{O}$ complexes where also the $\mathrm{n}-\sigma^{*}$ complex showed a red shift of $\sim 60 \mathrm{~cm}^{-1}$. The $\mathrm{n}-\sigma^{*}$ complex, which is unambiguously observed in our experiments, was not observed in the gas phase experiments.

In $\mathrm{O}-\mathrm{H} \cdots \pi$ complexes, $\mathrm{PhAc}$ acts as a proton acceptor; and, as is well known in such complexes, the $\equiv \mathrm{C}-\mathrm{H}$ frequency shows significantly smaller red shifts than those observed in $\equiv \mathrm{C}-\mathrm{H} \cdots \mathrm{O}\left(\mathrm{n}-\sigma^{*}\right)$ complexes. $^{9}$ Our computations for the $\mathrm{H}-\pi$ complexes indicated red shifts of $2 \mathrm{~cm}^{-1}$ and $5 \mathrm{~cm}^{-1}$ for complexes 2 and 3 , respectively, which were not evident in our experiments. It is possible that these features were probably masked by the Fermi resonance bands of PhAc occurring at $3309.2 / 3310.8 \mathrm{~cm}^{-1}$. It must be recalled that the $\mathrm{O}-\mathrm{H} \cdots \pi$ complex was observed in the gas phase experiments. ${ }^{15}$ Hence, experiments with isotopically substituted $\mathrm{PhAc}$ with deuterated acetylenic hydrogen $\left(\mathrm{PhAc}_{\mathrm{D}}\right)$ were performed to see if the features of the $\mathrm{O}-\mathrm{H} \cdots \pi$ complex could be observed in the isotopic molecule, which will be presented next.

3.1.3b $\equiv C-D$ stretch of $P h A c_{D}$ in $P h A c_{D}-M e O H:$ The $\equiv \mathrm{C}-\mathrm{D}$ stretch of $\mathrm{PhAc}_{\mathrm{D}}$ occurs at $2599.7 \mathrm{~cm}^{-1}$ in $\mathrm{N}_{2}$ matrix. The deuterium substituted $\mathrm{PhAc}\left(\mathrm{PhAc}_{\mathrm{D}}\right)$ does not show a Fermi resonance, as seen in $\mathrm{PhAc}$, due to the shift in $\equiv \mathrm{C}$-D stretch to a lower wavenumber and consequent suppression of Fermi resonance which involved the $\equiv \mathrm{C}-\mathrm{H}$ stetching mode. However, the $\mathrm{PhAc}_{\mathrm{D}}$ manifested site splitting as can be seen in Figure 3. An intense feature due to the $\equiv \mathrm{C}$-D stretch was observed at $2599.7 \mathrm{~cm}^{-1}$ in the $\mathrm{N}_{2}$ matrix, with site split features 
at 2602.6 and $2604.7 \mathrm{~cm}^{-1}$. With the absence of Fermi resonance diads, it was explored if the small shift in the $\equiv \mathrm{C}$-D stretch as a result of the formation of the $\mathrm{H}-\pi$ complex, could be observed.

3.1.3c Complex 1: When $\mathrm{PhAc}_{\mathrm{D}}$ and $\mathrm{MeOH}$ were codeposited, new product features were observed in the $\equiv \mathrm{C}$-D stretching region at $2554.7 \mathrm{~cm}^{-1}$, which was red shifted from the $\equiv \mathrm{C}$-D stretch of uncomplexed $\mathrm{PhAc}_{\mathrm{D}}$ by $45 \mathrm{~cm}^{-1}$. The computational studies predict a feature for $\mathrm{n}-\sigma^{*}$ complex at $2599.9 \mathrm{~cm}^{-1}$ which is red shifted by $52.3 \mathrm{~cm}^{-1}$ (Table 2). The experimental and computational observations agree very well; so this feature was assigned to Complex 1 ( $\left.\mathrm{n}-\sigma^{*}\right)$. This assignment further reassures the formation of the $n-\sigma^{*}$ (Complex 1).

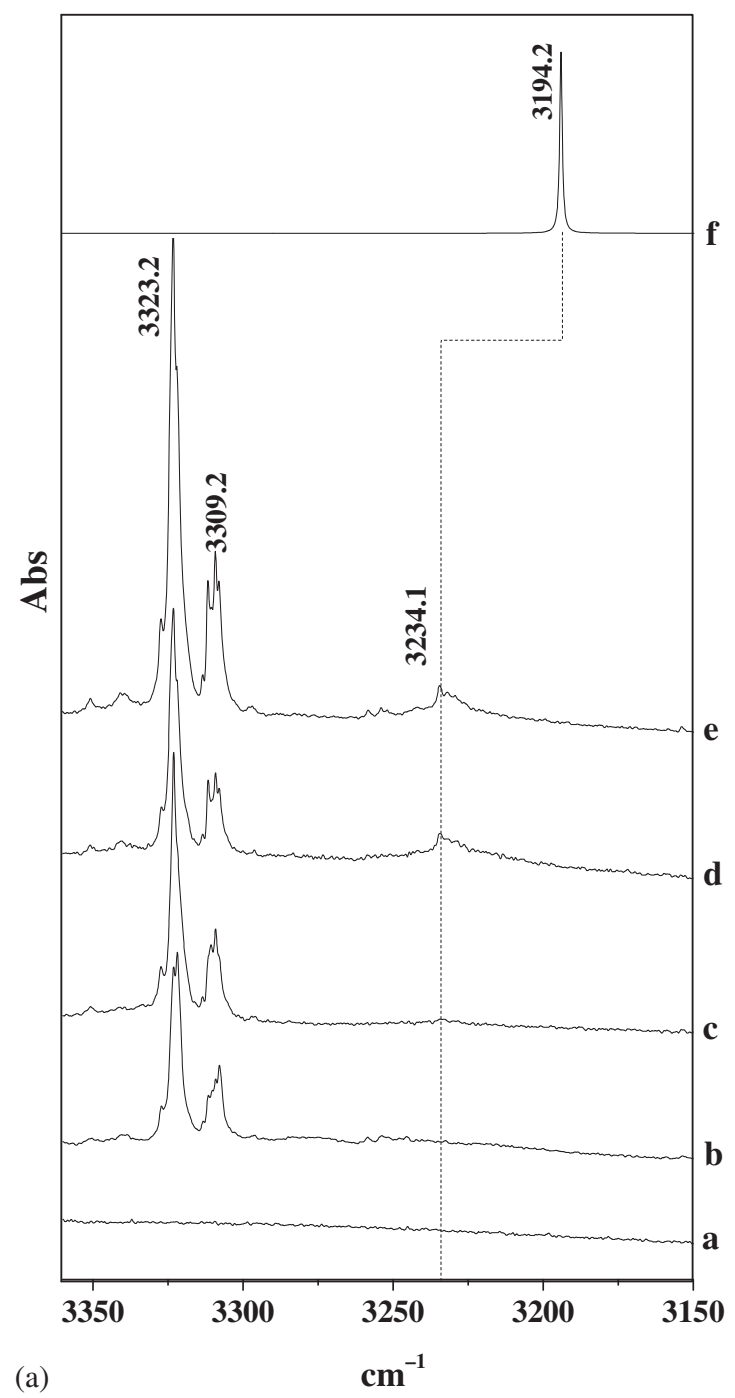

3.1.3d Complex 2/3: In the annealed matrices containing both $\mathrm{PhAc}_{\mathrm{D}}$ and $\mathrm{MeOH}$, a new feature at 2593.6 $\mathrm{cm}^{-1}$ was observed. This feature is red shifted from the feature due to uncomplexed $\mathrm{PhAc}_{\mathrm{D}}$ by $\sim 6 \mathrm{~cm}^{-1}$, and agrees with the computed shift of $2 \mathrm{~cm}^{-1}$ (Complex 2) or $3 \mathrm{~cm}^{-1}$ (Complex 3) for it to be due to a O-H. $\cdots \pi$ complex. Our data does not unambiguously point to Complex 2 or 3 , and we therefore refrain from making a firm assignment other than to say that the $\mathrm{O}-\mathrm{H} \cdots \pi$ complex was observed.

\subsubsection{O-H stretch of $\mathrm{MeOH}$ in $\mathrm{PhAc}-\mathrm{MeOH}$}

3.1.4a Complex 1: The O-H stretching frequency of $\mathrm{MeOH}$ occurs at $3666.2 \mathrm{~cm}^{-1}$ in a $\mathrm{N}_{2}$ matrix. In Complex 1, the $\mathrm{O}-\mathrm{H}$ stretch of $\mathrm{MeOH}$ was computed to

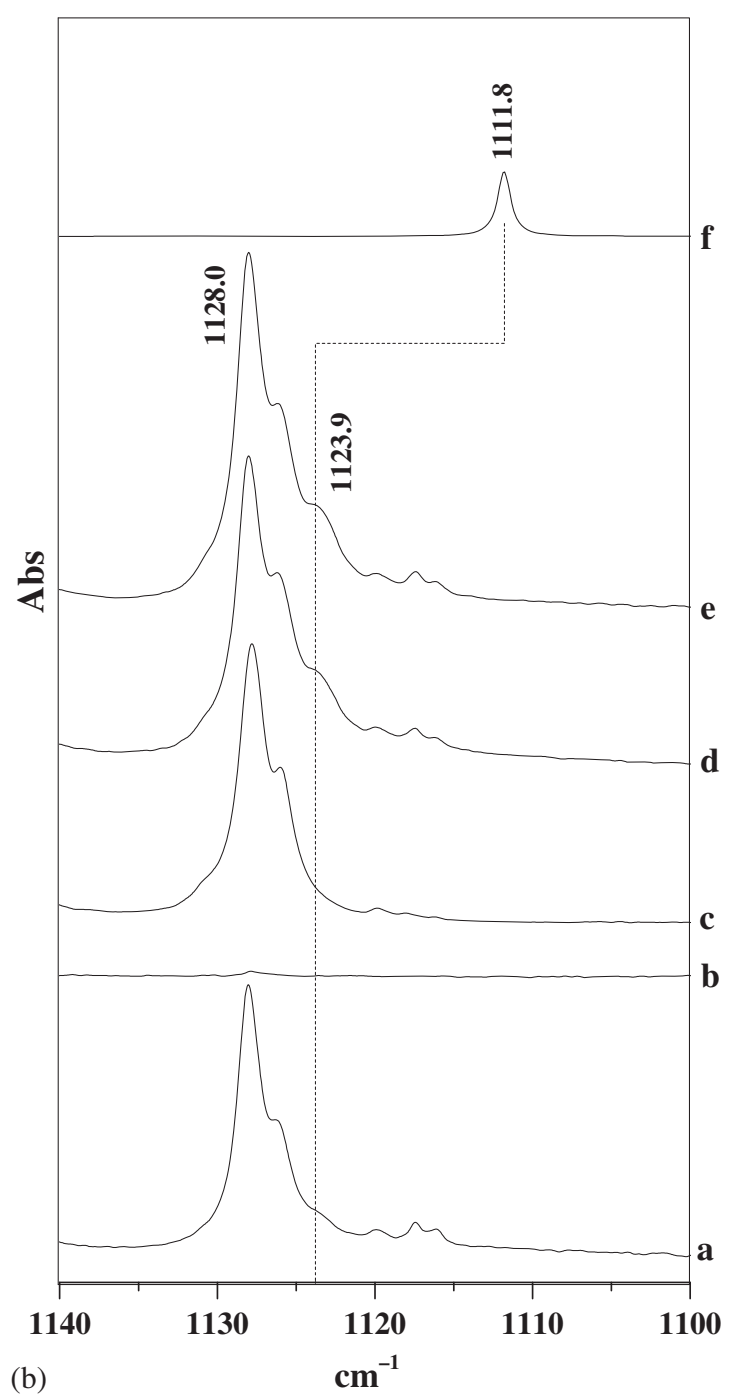

Figure 5. Annealed spectra of $\mathrm{PhAc}, \mathrm{DEE}$ and $\mathrm{PhAc}-\mathrm{DEE}$ complex in $\equiv \mathrm{CH}$ stretching region of $\mathrm{PhAc}$ (3360-3150 $\mathrm{cm}^{-1}$ ) in Grid A and C-O stretching region of DEE (1140-1100 $\mathrm{cm}^{-1}$ ) in Grid B. (a) DEE: $\mathrm{N}_{2}$ (0.25:1000) (b) PhAc: $\mathrm{N}_{2}$ (1:1000) (c) $12 \mathrm{~K}$ spectrum of PhAc:DEE:N ${ }_{2}$ (1:1:1000) (d) PhAc:DEE: $\mathrm{N}_{2}$ (1:1:1000). (e) PhAc:DEE: $\mathrm{N}_{2}(2: 1: 1000)$ (f) Computed Spectra of $n-\sigma^{*}$ complex at MP2/aug-cc-pVDZ level of theory. 
occur at $3660.7 \mathrm{~cm}^{-1}$ which amounts to a red shift of 4 $\mathrm{cm}^{-1}$ from that of uncomplexed $\mathrm{MeOH}$. However, we did not discern any feature that could be assigned to this feature in the matrix, even though the formation of Complex 1 was unambiguously indicated through the shifts in the $\equiv \mathrm{C}-\mathrm{H}$ stretch.

3.1.4b Complex 2/3: In the codeposition experiments of $\mathrm{PhAc}$ and $\mathrm{MeOH}$, new product bands in $\mathrm{O}-\mathrm{H}$ stretching region were observed at 3593.9 and $3590.6 \mathrm{~cm}^{-1}$ which are, respecitively, red shifted by 70.3 and 73.6 $\mathrm{cm}^{-1}$ from the $\mathrm{O}-\mathrm{H}$ stretch of uncomplexed $\mathrm{MeOH}$ at $3666.2 \mathrm{~cm}^{-1}$ (Figure 2, Table 2). Such large red shifts are generally indicative of complexes where $\mathrm{MeOH}$ is a proton donor, which in this case would imply the formation of a $\mathrm{O}-\mathrm{H} \cdots \pi$ complex. It can be observed from Table 2 that the observed shifts are in agreement with the $\mathrm{O}-\mathrm{H} \cdots \pi$ type complexes, which are computed to show a red shift of 40.6 and $47.2 \mathrm{~cm}^{-1}$ for Complex 2 and 3, respectively. Hence, these product features can be undoubtedly assigned to $\mathrm{O}-\mathrm{H} \cdots \pi$ complex of $\mathrm{PhAc}-\mathrm{MeOH}$ adducts. However, once again it is impossible for us to assign these features firmly to either Complex 2 or 3. We only assert that the O-H $\cdots \pi$ complexes are observed in the matrix in addition to the $\mathrm{n}-\sigma^{*}$.

\subsection{PhAc-DEE Complex}

While the computed and observed frequency shifts for the $\mathrm{n}-\sigma^{*}$ complex of $\mathrm{PhAc}-\mathrm{MeOH}$ were in agreement, we looked for an independent confirmation for the presence of this complex. Towards this end, we studied the PhAc-DEE system, which can be expected to manifest only an $\mathrm{n}-\sigma^{*}(\equiv \mathrm{C}-\mathrm{H} \cdots \mathrm{O})$ complex. A comparison of the shift of the $\equiv \mathrm{C}-\mathrm{H}$ frequency observed in this system with that observed for the systems studied earlier, $\mathrm{PhAc}-\mathrm{MeOH}$ and $\mathrm{PhAc}-\mathrm{H}_{2} \mathrm{O}$, would provide unequivocal proof for the existence or not of the $n-\sigma^{*}$ complex in these experiments. Diethylether (DEE) was used in these experiments owing to its more ready availability than dimethylether.

3.2.1 Experimental: When PhAc and DEE were codeposited and the matrix then annealed, new product bands were observed at $3194.2 \mathrm{~cm}^{-1}$ and $1123.9 \mathrm{~cm}^{-1}$ (Figure 5). Concentration dependence of these features further proved their assignment to a 1:1 PhAc-DEE complex. Experiments with $\mathrm{PhAc}_{\mathrm{D}}$ and $\mathrm{DEE}$ yielded product features at $2554.7 / 2552.8 \mathrm{~cm}^{-1}$ and 1123.9 $\mathrm{cm}^{-1}$ (Figure 6).

3.2.2 Computational: DEE can serve only as a hydrogen bond acceptor, since it has only one basic site at

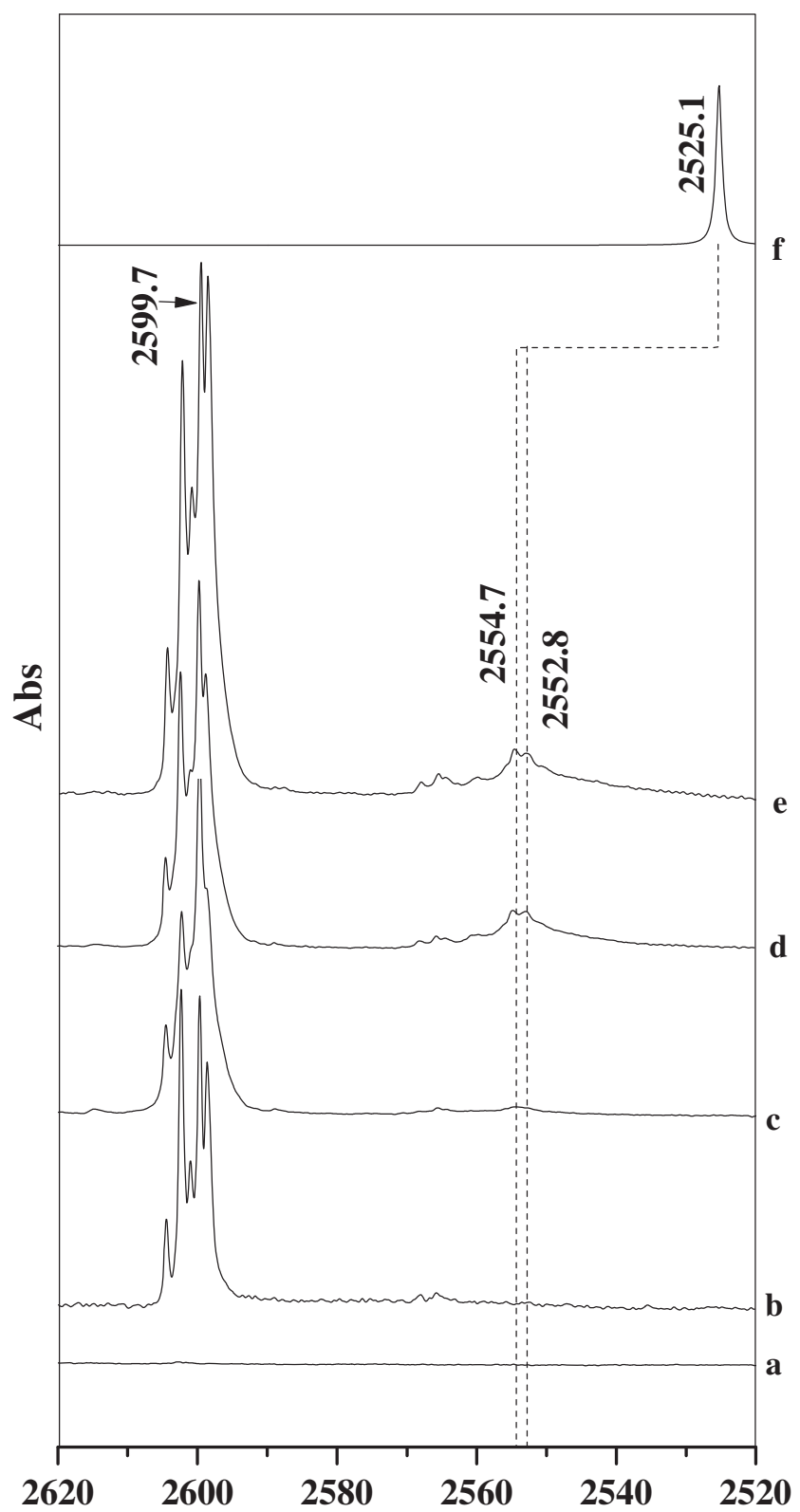

Figure 6. Annealed spectra of PhAcD, DEE and PhAcDDEE complex in $\equiv \mathrm{CD}$ stretching region of $\mathrm{PhAcD}$ (2620-2520 $\left.\mathrm{cm}^{-1}\right)$. (a) DEE: $\mathrm{N}_{2}(0.25: 1000)$ (b) PhAcD: $\mathrm{N}_{2}$ (3:1000) (c) $12 \mathrm{~K}$ spectrum of PhAcD:DEE: $\mathrm{N}_{2}$ (3:0.5:1000) (d) PhAcD:DEE:N ${ }_{2} \quad(3: 0.5: 1000)$. (e) PhAcD:DEE:N $\mathrm{N}_{2}$ $(3: 1: 1000)$ (f) Computed Spectra of $n-\sigma^{*}$ complex at MP2/aug-cc-pVDZ level of theory.

the oxygen atom, with no sufficiently acidic proton for proton donation. Incidentally, the presence of two ethyl chains on oxygen, leads to the possibility of conformers in DEE. At the MP2/aug-cc-pVDZ level four conformers of diethyl ether were found, as shown in Figure S1 (Supplementary Information). It can be seen that the conformers arise due to the relative orientation of the terminal carbon atoms; the four conformers 
being labelled as $\mathrm{TT}, \mathrm{TG}, \mathrm{G}^{+} \mathrm{G}^{-}, \mathrm{G}^{ \pm} \mathrm{G}^{ \pm}$. In the TT conformer all the carbon atoms and the oxygen, adopt an all-trans orientation, while in the gauche conformer the terminal carbon atom has a staggered orientation. The TT conformer is the global minimum, while progressive change of the terminal carbon to adopt a gauche orientations raises the energy, as shown in Figure S1 (Supplementary Information), which shows both the structures and the relative energies of the various conformers. While the TT structure is the global minimum as it experiences the least steric interaction, the TG and GG conformers adopt a gauche orientation, stabilized by a $\mathrm{n} \rightarrow \sigma_{\mathrm{C}-\mathrm{C}} *$ delocalization, as revealed through an NBO analysis. A similar effect, referred to as the anomeric effect, operates in many compounds with heteroatoms such as dimethoxymethanes, where the anomeric stabilization is so strong, that it dominates over the steric interaction, leading to the molecule adopting a GG conformer as the ground state. ${ }^{29}$

Based on the relative energies and the conformational degeneracies of the different confomers of DEE, the population of the TT, TG, $\mathrm{G}^{+} \mathrm{G}^{-}, \mathrm{G}^{ \pm} \mathrm{G}^{ \pm}$can be calculated to be in the ratio of $79.4: 17.5: 1.6: 1.6$. Since the dominant population is due to the TT conformer, all computations were done for the complexes with DEE in this conformation.

Figure 7 shows the structure of the PhAc-DEE complex with DEE in the TT conformation. As expected, the PhAc-DEE complex turns out to be an n- $\sigma^{*}$ complex with PhAc acting as proton donor through $\equiv \mathrm{C}-\mathrm{H}$ to the oxygen atom of DEE. Table S2 (Supplementary Information) gives structural parameters of this complex. The stabilization energy of PhAc-DEE complex at various levels of theory is given in Table 3.

\subsubsection{Vibrational Assignments}

3.2.3a $\equiv C-H$ stretch of PhAc in PhAc-DEE: Figure 5 shows the $\equiv \mathrm{CH}$ stretching region of PhAc spanning from $3360-3150 \mathrm{~cm}^{-1}$. The vibrational feature observed at $3194.2 \mathrm{~cm}^{-1}$ shows a red shift of $89.0 \mathrm{~cm}^{-1}$ from the same mode in uncomplexed PhAc, which agrees reasonably well with the computed shift (Table 4). The shift observed for PhAc-DEE $n-\sigma^{*}$ complex is similar in magnitude and direction to the red shift observed for the $\mathrm{n}-\sigma^{*}$ complex of $\mathrm{PhAc}-\mathrm{MeOH}$ and $\mathrm{PhAc}-\mathrm{H}_{2} \mathrm{O}$ (Table 2), which independently and convincingly proves the existence of the $n-\sigma^{*}$ complex in the matrix; a structure that eluded observation in the molecular beam studies.

3.2.3b C-O stretch of DEE in PhAc-DEE complex: The C-O stretch of the TT conformer of DEE in TT in the $\mathrm{N}_{2}$ matrix is oserved at $1128.0 \mathrm{~cm}^{-1}$ (Figure 5). The product feature corresponding to the PhAc-DEE complex was observed as a shoulder at $1123.9 \mathrm{~cm}^{-1}$ (Figure 5), amounting to a red shift of $4.1 \mathrm{~cm}^{-1}$. This

Table 3. Computed interaction energies Raw/ZPE/BSSE $(\mathrm{kJ} / \mathrm{mol})$ of PhAc-DEE $\mathrm{n}-\sigma^{*}$ complex, at various levels of theory and basis sets. CCSD values are uncorrected interaction energies obtained using single point energy calculations at the geometries optimized at the MP2 level and the corresponding basis sets.

\begin{tabular}{lcc}
\hline Level/Basis Set & $\mathbf{6 - 3 1 1}++\mathbf{G}(\mathbf{d}, \mathbf{p})$ & aug-cc-pVDZ \\
\hline M06-2X & $-18.0 /-15.1 /-16.4$ & $-18.0 /-15.1 /-15.1$ \\
MP2 & $-21.0 /-11.8 /-13.4$ & $-27.3 /-23.8 /-16.8$ \\
CCSD & -17.2 & -21.6 \\
\hline
\end{tabular}

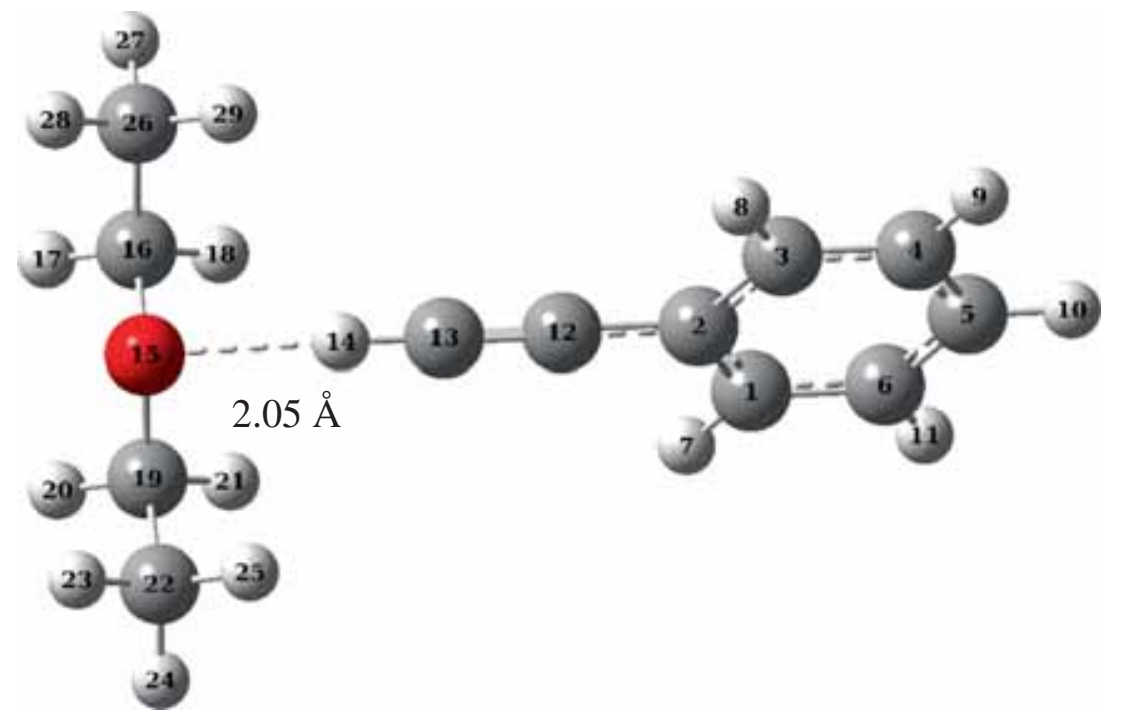

Figure 7. Optimised geometry of PhAc-DEE $n-\sigma^{*}$ complex at MP2/aug-cc-pVDZ level of theory. 
Table 4. Experimental and scaled computed wavenumbers $\left(\mathrm{cm}^{-1}\right)$ of $\mathrm{PhAc} / \mathrm{PhAc} \mathrm{C}_{\mathrm{D}}$ and DEE in PhAc-DEE and $\mathrm{PhAc}_{\mathrm{D}}$-DEE complex computed at the MP2/aug-ccpVDZ level of theory.

\begin{tabular}{lccc}
\hline \multicolumn{2}{c}{ Experimental $\left(\mathrm{N}_{2}\right.$ matrix $)$} & $\begin{array}{c}\text { Scaled Computed } \\
\mathrm{n}-\sigma^{*} \text { Complex }\end{array}$ & Mode Assignment \\
\hline Phac & Complex & & \\
3323.2 & 3234.1 & $(-129.0)$ & $\equiv \mathrm{C}-\mathrm{H}$ stretch \\
$\mathrm{DEE}$ & $(-\mathbf{8 9 . 0})^{\mathbf{1}}$ & 1111.8 & $\mathrm{C}-\mathrm{O}$ stretch \\
1128.0 & 1123.9 & $(-16.2)$ & \\
$\mathrm{Phac}_{\mathrm{D}}$ & $(-\mathbf{4 . 1})$ & 2525.1 & $\equiv \mathrm{CD}$ stretch \\
2599.7 & $2554.7 / 2552.8$ & $(-74.6)$ & \\
& $(\mathbf{- 4 5 . 0}) /(-\mathbf{4 6 . 8})$ & & \\
\hline
\end{tabular}

Scaling Factor $\left(1630-500 \mathrm{~cm}^{-1}\right)=0.97992$.

Scaling Factor $\left(3500-2000 \mathrm{~cm}^{-1}\right)=0.95460$.

Scaling Factor $=0.97128$ for $\mathrm{PhAc}_{\mathrm{D}}$-DEE complex.

${ }^{1} \Delta v=v_{\text {complex }}-v_{\text {monomer }}$.

Table 5. AIM calculations performed using wavefunctions obtained at MP2/aug-cc-pVDZ for 1:1 PhAc-MeOH and PhAcDEE complexes.

\begin{tabular}{|c|c|c|c|c|c|c|c|}
\hline Complex & $\rho\left(\mathbf{r}_{\mathbf{c}}\right)$ & $\nabla^{2} \rho\left(\mathbf{r}_{\mathbf{c}}\right)$ & $\lambda_{1}$ & $\lambda_{2}$ & $\lambda_{3}$ & $\lambda_{1} / \lambda_{3}$ & $\left(\lambda_{1} / \lambda_{2}\right)-1$ \\
\hline \multicolumn{8}{|c|}{ PhAc-MeOH } \\
\hline Complex 1 C-H $\cdots$ O & 0.0176 & 0.0573 & -0.0207 & -0.0196 & 0.0976 & 0.2124 & 0.0601 \\
\hline Complex 2 C $\cdots \mathrm{H}-\mathrm{O}$ & 0.0101 & 0.0296 & -0.0076 & -0.0022 & 0.0394 & 0.1935 & 2.5386 \\
\hline Complex 3 C $\cdots$ H-O & 0.0111 & 0.0326 & -0.0097 & -0.0062 & 0.0486 & 0.1998 & 0.5554 \\
\hline Complex 3 C-H $\cdots C$ & 0.0084 & 0.0280 & $\begin{array}{l}-0.0057 \\
\text { PhAc-DEE }\end{array}$ & -0.0010 & 0.0347 & 0.1637 & 4.4725 \\
\hline $\mathbf{n}-\sigma * \mathbf{C}-\mathbf{H} \cdots \mathbf{O}$ & 0.0224 & 0.0688 & -0.0276 & -0.0262 & 0.1226 & 0.2250 & 0.0520 \\
\hline
\end{tabular}

observation corrobrates well with the computed value for the $n-\sigma^{*}$ complex thereby further confirming the observation of $n-\sigma^{*}$ complex (Table 4).

3.2.3c $\equiv C-D$ stretch of $P h A c_{D}$ in $P h A c_{D}-D E E$ : Figure 6 shows the spectrum over the region of the $\equiv C$-D stretch of $\mathrm{PhAc}_{\mathrm{D}}$. The product feature for the $\mathrm{PhAc}_{\mathrm{D}}-\mathrm{DEE}$ was observed at $2554.7 / 2552.8 \mathrm{~cm}^{-1}$, which amounts to a red shift of $\sim 45 \mathrm{~cm}^{-1}$ from the feature of $\equiv \mathrm{C}$-D stretch of uncomplexed $\mathrm{PhAc}_{\mathrm{D}}$ at $2599.7 \mathrm{~cm}^{-1}$ in agreement with the computations (Table 4). The isotopic shift further corroborates the trapping of the $\mathrm{n}-\sigma^{*}$ complex in the matrix.

\subsection{AIM analysis}

An examination of charge density topology was performed using the atoms-in-molecules (AIM) theory of Bader, ${ }^{30}$ with wavefunctions generated at the MP2/augcc-pVDZ level of theory. $(3,-1)$ bond critical points corresponding to the weak intermolecular interactions in Complex 1, 2 and 3 of $\mathrm{PhAc}-\mathrm{MeOH}$ and the $\mathrm{n}-\sigma^{*}$ complex of PhAc-DEE are shown in the Figure S2
(Supplementary Information). Values of electron density $\rho\left(\mathrm{r}_{\mathrm{c}}\right)$, eigenvalues of the Hessian, $\lambda_{1}, \lambda_{2}, \lambda_{3}$, the Laplacian $\left(\nabla^{2} \rho\right)$ of electron density (defined as the sum of the eigenvalues), the ellipticity, $\left[\left(\lambda_{1} / \lambda_{2}\right)-1\right]$ and $\left|\lambda_{1} / \lambda_{3}\right|$, for all the complexes, computed at the bond critical points, are shown in Table 5 .

3.3.1 PhAc-MeOH Complexes: Complex 1 shows a bond critical point (BCP 1) having $\equiv \mathrm{C}-\mathrm{H} \cdots \mathrm{O}$ type of interaction. (Figure S2 in Supplementary Information). It can be seen that the electron density at BCP of the $\mathrm{n}-\sigma^{*}$ complex is the largest amongst all three complexes. While Complex 2 shows more than one BCP between $\mathrm{PhAc}$ and $\mathrm{MeOH}$, the interaction between the $\mathrm{O}-\mathrm{H}$ of $\mathrm{MeOH}$ and the carbon of phenyl appears to be the dominant interaction as revealed by its electron density. This parameters corresponding to this $\mathrm{BCP}$ alone is presented in Table 5. Complex 3 shows two simultaneous interactions between $\mathrm{PhAc}$ and $\mathrm{MeOH}$ which have comparable electron densities at both the BCPs. It can be seen that the values of $\rho\left(r_{c}\right)$ for all these systems fall in the range of hydrogen bonding complexes proposed by Koch and Popelier. ${ }^{31,32}$ 
We have also compared the ratio $\lambda_{1} / \lambda_{3}$, and these values are approximately equal to but less than 0.25 (Table 5), which is indicative of a closed shell interaction. Ellipticity at the bond critical point which is given by $\left[\left(\lambda_{1} / \lambda_{2}\right)-1\right]$, was also calculated for all the complexes. In complex 1 , the ellipticity is close to zero for the $\equiv \mathrm{C}-\mathrm{H} \cdots \mathrm{O}$ interaction, indicating a bond with a cylindrical symmetry, while the large values of ellipticity for Complex 2 and C-H... C interaction in Complex 3 , indicating the accumulation of charge in a plane.

3.3.1 PhAc-DEE Complex: It can be seen that in $\mathrm{PhAc}-\mathrm{DEE}$, the electron density at the only BCP corresponding to the $\mathrm{n}-\sigma^{*}$ intermolecular interaction is 1.3 times larger compared with that in the $\mathrm{n}-\sigma^{*}$ complex of PhAc-MeOH (Table 5), indicating the DEE complex to be stronger than the $\mathrm{MeOH}$ complex, which is consistent with the larger interaction energy computed for the DEE complex compared with the $\mathrm{MeOH}$ complex of $\mathrm{PhAc}$ at the same level of theory.

\subsection{NBO Analysis}

NBO analysis on the PhAc-MeOH and PhAc-DEE systems was also performed to understand the nature of bonding interactions between donor-acceptor orbitals, the results of which are shown in Table 6. In this table, we have shown the second order perturbation energies (E), the energy difference between the donor and acceptor orbitals $[E(j)-E(i)]$ and the overlap between the two orbitals $[\mathrm{F}(\mathrm{i}, \mathrm{j})]$.

3.4.1 PhAc-MeOH Complexes: Complex 1, with an $\mathrm{n}-\sigma^{*}$ interaction, involves the delocalization of electron density from the lone pair on oxygen to the antibonding orbital on $\equiv \mathrm{C}-\mathrm{H}$ of PhAc (proton donor). The value of second order perturbation energy for this complex shows that it is the strongest interaction possibly because of higher value of overlap integral. Complex 2 and Complex 3 both have comparatively smaller second order perturbation values as compared to Complex $1\left(n-\sigma^{*}\right)$ indicating that $\equiv \mathrm{C}-\mathrm{H} \cdots \mathrm{O}$ interaction to be stronger than $\mathrm{O}-\mathrm{H} \cdots \pi$ interaction. However, the $\mathrm{O}-\mathrm{H} \cdots \pi$ complexes turn out to be stronger and represent the global minima, probably due to multiple contacts.

3.4.2 PhAc-DEE Complex: Table 6 shows the results for PhAc-DEE $\mathrm{n}-\sigma^{*}$ complex. The large value for the second order perturbation energy indicates a stronger $\mathrm{n}-\sigma^{*}$ interaction in the PhAc-DEE complex than in the $\mathrm{MeOH}$ complex, consistent with the fact that DEE is a stronger proton acceptor than $\mathrm{MeOH}$.

\subsection{Energy Decomposition Analysis}

Localised Molecular Orbital Energy Decomposition Analysis Scheme (LMOEDA) was done to partition interaction energy of the various complexes of $\mathrm{PhAc}-\mathrm{MeOH}$ and $\mathrm{PhAc}-\mathrm{DEE}$ into individual contributing energy component, electrostatic $\mathrm{E}_{\mathrm{ES}}$, exchangerepulsion $\mathrm{E}_{\mathrm{ER}}$, polarization $\mathrm{E}_{\mathrm{POL}}$ and dispersion $\mathrm{E}_{\mathrm{DIS}}$. Table 7 lists the contribution of various energy components to the total interaction energy.

In Complex 1 of the $\mathrm{PhAc}-\mathrm{MeOH}$ adduct, the major contribution to the interaction energy is from the electrostatic component while polarization and dispersive components have smaller contributions. This picture is similar to that computed for the $n-\sigma^{*}$ complexes of $\mathrm{PhAc}-\mathrm{H}_{2} \mathrm{O}$. Complex 2 and Complex 3 present an interesting scenario; both are isoenergetic $\mathrm{O}-\mathrm{H} \cdots \pi$ complexes but the energy decomposition pattern of both complexes show contrasting features. In Complex 2 dispersion interaction is the major component followed by electrostatic, while in Complex 3 both dispersive and electrostatic components are almost equal contributors to the total interaction energy. In the PhAc-DEE $n-\sigma^{*}$

Table 6. $\mathrm{NBO}$ analysis for $\mathrm{PhAc}-\mathrm{MeOH}$ and PhAc-DEE complexes, performed at MP2/augcc-pVDZ level of theory. The atom numbering indicated in table is as shown in Figures 4 and 7. $E$ is the second order perturbation energy $(\mathrm{kJ} / \mathrm{mol}), E(\mathrm{j})-\mathrm{E}(\mathrm{i})$ is the donor-acceptor energy difference and $F(i, j)$ is the overlap between the donor and acceptor orbitals.

\begin{tabular}{llcccc}
\hline & \multicolumn{2}{c}{ Orbitals involved } & & & \\
\cline { 2 - 4 } System & Donor & Acceptor & $\mathrm{E}(\mathrm{kJ} / \mathrm{mol})$ & $\mathrm{E}(\mathrm{j})$-E(i) a.u. & $\mathrm{F}(\mathrm{i}, \mathrm{j})$ a.u. \\
\hline \multirow{5}{*}{ Complex 1 } & $\mathrm{O}_{15}(\mathrm{n})$ & $\mathrm{C}_{13}-\mathrm{H}_{14}\left(\sigma^{*}\right)$ & 17.8 & 1.32 & 0.067 \\
Complex 2 & $\mathrm{C}_{5}-\mathrm{C}_{6}(\sigma)$ & $\mathrm{O}_{15}-\mathrm{H}_{16}\left(\sigma^{*}\right)$ & 6.3 & 1.07 & 0.039 \\
Complex 3 & $\mathrm{C}_{12}-\mathrm{C}_{13}(\sigma)$ & $\mathrm{O}_{15}-\mathrm{H}_{16}\left(\sigma^{*}\right)$ & 7.2 & 1.16 & 0.040 \\
& \multicolumn{5}{c}{$\mathrm{PhAc-DEE}$} \\
$\mathrm{n}-\sigma^{*}$ complex & $\mathrm{O}_{15}(\mathrm{n})$ & $\mathrm{C}_{13}-\mathrm{H}_{14}\left(\sigma^{*}\right)$ & 25.4 & 1.27 & 0.079 \\
\hline
\end{tabular}


Table 7. Energy Decomposition analysis of PhAc-MeOH and PhAc-DEE complexes at MP2/aug-cc-pVDZ. All energies are given in $\mathrm{kJ} / \mathrm{mol}$.

\begin{tabular}{|c|c|c|c|c|c|c|c|c|}
\hline Complex & $\mathbf{E}_{\mathrm{ES}}$ & $\mathbf{E}_{\mathbf{E R}}$ & $\mathbf{E}_{\text {Pol }}$ & $\mathbf{E}_{\text {Disp }}$ & $\mathbf{E}_{\text {Total }}$ & $\mathbf{E}_{\mathbf{E S}} / \mathbf{E}_{\text {Total }}$ & $\mathbf{E}_{\text {Pol }} / \mathbf{E}_{\text {Total }}$ & $\mathbf{E}_{\text {Disp }} / \mathbf{E}_{\text {Total }}$ \\
\hline \multicolumn{9}{|c|}{ PhAc-MeOH } \\
\hline Complex 1 & -22.0 & 21.2 & -6.4 & -5.9 & -13.1 & 1.68 & 0.49 & 0.45 \\
\hline Complex 2 & -18.4 & 34.6 & -6.8 & -26.5 & -17.1 & 1.08 & 0.40 & 1.55 \\
\hline Complex 3 & -21.0 & 36.2 & -7.1 & -25.1 & -17.0 & 1.23 & 0.42 & 1.48 \\
\hline \multicolumn{9}{|c|}{ PhAc-DEE } \\
\hline n- $\sigma *$ Complex & -27.9 & 36.9 & -9.3 & -16.8 & -17.2 & 1.63 & 0.54 & 0.98 \\
\hline
\end{tabular}

complex too, the electrostatic component is the largest contributor to the interaction energy.

It therefore appears that all the $n-\sigma^{*}$ type complexes observed in our studies receive contributions from the electrostatic components, wheras the $\mathrm{O}-\mathrm{H} \cdots \pi$ complexes show dispersive interactions.

\section{Conclusions}

Hydrogen bonded complexes of PhAc-MeOH and PhAc-DEE were studied using matrix isolation infrared spectroscopy and ab initio calculations. Gas phase studies on the $\mathrm{PhAc}$ complexes with $\mathrm{H}_{2} \mathrm{O}$ and $\mathrm{MeOH}$ identified only the $\mathrm{O}-\mathrm{H} \cdots \pi$ complexes which was the global minimum and not the $n-\sigma^{*}$ complex that was a local minimum. In our experiments, we clearly identified the $\mathrm{n}-\sigma^{*}$ complex in both $\mathrm{PhAc}-\mathrm{H}_{2} \mathrm{O}$ and $\mathrm{PhAc}-\mathrm{MeOH}$. In the case of $\mathrm{PhAc}-\mathrm{MeOH}$, both $\mathrm{n}-\sigma^{*}$ and $\mathrm{O}-\mathrm{H} \cdots \pi$ complex were observed in $\mathrm{N}_{2}$ and Ar matrices. The $\mathrm{n}-\sigma^{*}$ complex was identified through the large shifts in the $\equiv \mathrm{C}-\mathrm{H}$ vibrational wavenumbers, which corroborated with our computations. However, in an effort to independently verify this observation, we performed experiments with PhAc-DEE which is contrained to form only the $\mathrm{n}-\sigma^{*}$ complex. The $\equiv \mathrm{C}-\mathrm{H}$ shift observed in the PhAc-DEE was $\sim 90 \mathrm{~cm}^{-1}$ to the red. Reassuringly, the shift in the same mode in both the $\mathrm{H}_{2} \mathrm{Oand} \mathrm{MeOH}$ complexes was comparable thus providing unequivocal evidence for the observation of the $\mathrm{n}-\sigma^{*}$ complex. It might not be out of place to mention that in the case of $\mathrm{C}_{2} \mathrm{H}_{2}$, complexes with $\mathrm{H}_{2} \mathrm{O}$ and $\mathrm{MeOH}$ yield the $\mathrm{n}-\sigma^{*}$ complex as the global minimum. The dual interactions observed in the case of the $\mathrm{H}-\pi$ complex in $\mathrm{PhAc}$, causes a reversal in the energy ordering in the $\mathrm{O}-\mathrm{H} \cdots \pi$ and $n-\sigma^{*}$ complex compared with $\mathrm{C}_{2} \mathrm{H}_{2}$. The PhAc complexes with $\mathrm{MeOH}$ and DEE were also studied using AIM, NBO and EDA methodologies, to understand the nature of the interactions.

It may also be noted that the $n-\sigma^{*}$ complex was the strongest in PhAc-DEE in keeping with the increased basicity of the ether compared with the other precursors studied.

\section{Supplementary Information (SI)}

The electronic supporting information can be seen at www.ias.ac.in/chemsci.

\section{Acknowledgements}

GK and MF gratefully acknowledge the fellowship from DST and MHRD, respectively. The authors are also grateful to IISER Mohali, India for the facilities.

\section{References}

1. Zhao H, Jiamin Chang J and Du L 2016 Comput. Theor. Chem. 1084126

2. Arunan E et al. 2011 Pure Appl. Chem. 831619

3. Grant J H and Legon A C 2015 Phys. Chem. Chem. Phys. 17858

4. Arunan E and Mani D 2015 Faraday Discuss 17751

5. Nishio M, Hirota M and Umezawa Y $1998 \mathrm{The} C H / \pi$ interaction, Evidence, Nature and Consequences (New York: Wiley-VCH)

6. Matsuura H, Yoshida H, Hieda M, Yamanaka S, Harada T, Shin-ya K and Ohno K 2003 J. Am. Chem. Soc. 125 13910

7. Matsuura H, Yoshida H, Hieda M, Yamanaka S, Harada T, Shin-ya K and Ohno K 2003 J. Am. Chem. Soc. 125 13910

8. Engdahl A and Nelander B 1985 J. Chem. Phys. 892860

9. Jose K V J, Gadre S R, Sundararajan K and Viswanathan K S 2007 J. Chem. Phys. 127104501

10. Viswanathan K S, Sankaran K and Sundararajan K 2000 In Encyclopedia of Analytical Chemistry J B Myers (Ed.) (New York: Wiley)

11. Whittle E, Dows D A and Pimentel G C 1954 J. Chem. Phys. 221943

12. Karir G and Viswanathan K S 2016 J. Mol. Struct. 1107 145

13. Singh P C, Bandyopadhyay B and Patwari G N $2008 \mathrm{~J}$. Phys. Chem. A 1123360

14. Goswami M and Arunan E 2011 Phys. Chem. Chem. Phys. 1314153

15. Singh P C and Patwari G N 2008 J. Phys. Chem. A 112 5121

16. Venkatesan V, Sundararajan K and Viswanathan K S 2002 J. Phys. Chem. A 1067707

17. Kar B P, Ramanathan N, Sundararajan $K$ and Viswanathan K S 2012 J. Mol. Struct. 102484 
18. Sundararajan K and Viswanathan K S $2006 \mathrm{~J}$. Mol. Struct. 798109

19. Saini J and Viswanathan K S 2016 J. Mol. Struct. 1118 147

20. Frisch M J, Trucks G W, Schlegel H B, Scuseria G E, Robb M A, Cheeseman J R, Scalmani G, Barone $\mathrm{V}$, Mennucci B, Peterson G A, Montgomery J A, Raghavachari K, Al-Laham M A, Zakrzewski V G, Ortiz J V, Foresman J B, Cioslowski J, Stefanov B B, Nanayakkara A, Challacombe M, Peng C Y, Ayala P Y, Chen W, Wong M W, Andres J L, Replogle E S, Gomperts R, Martin R L, Fox D J, Binkley J S, Defrees D J, Baker J, Stewart J P, Head-Gordon M, Gonzalez C and Pople J A 2010 GAUSSIAN 09 Revision C.01 (Gaussian Inc.: Wallingford CT)

21. The spectra were simulated using SYNSPEC made available by Irikura K, 1995 National Institute of Standards and Technology, Gaithesburg, MD 20899, USA

22. Boys S F and Bernardi F 1970 Mol. Phys. 19553
23. Blieger-König F, Bayles D and Schönbohn J AIM2000 (Version 1.0): Chemical Adviser: Bader R F W

24. Glendening E D, Carpenter J E, and Weinhold F, NBO (Version 3.1)

25. Su P F and Li H 2009 J. Chem. Phys. 131014102

26. Schmidt M W, Baldridge K K, Boatz J A, Elbert S T, Gordon M S, Jensen J H, Koseki S, Matsunaga N, Nguyen K A, Su S, Windus T L, Dupuis M and Montgomery J A 1993 J. Comp. Chem. 141347

27. King G W and So S P 1970 J. Mol. Spectrosc. 36468

28. Stearns J A and Zwier T S 2003 J. Phys. Chem. A 107 10717

29. Venkatesan V, Sundararajan K, Sankaran K and Viswanathan K S 2002 Spectrochim. Acta Part A 58467

30. Bader R F W 1994 In Atoms in Molecules: A Quantum Theory (Oxford: Clarendon Press)

31. Koch U and Popelier P L A 1995 J. Phys. Chem. 999747

32. Popelier P L A 2000 In Atoms in Molecules: An introduction (London: Prentice Hall) 